\title{
Distribution and Migration of Moisture in Round Bamboo in Response to Microwave Drying
}

\author{
Huang-fei Lv, ${ }^{\text {a,\# }}$ Mei-ling Chen, ${ }^{\text {,\# }}$ Cai-ping Lian, ${ }^{\mathrm{b}}$ Hui Li, ${ }^{\mathrm{c}, \mathrm{d}}$ Shu-min Yang, ${ }^{\mathrm{b}}$ Bin Xu, ${ }^{\mathrm{a}, *}$ \\ and Ben-hua Fei ${ }^{b} *$
}

\begin{abstract}
Characterized by its light weight, high strength, and good flexibility, round bamboo is a natural functional biomaterial with a multi-level structure. Cracking is a key factor hindering its wider application. Moisture changes cause cracking when the round bamboo is dried. Therefore, studying moisture variations in the drying process of round bamboo can effectively reduce or solve the cracking problem. In this study, microwave drying with computer tomography (CT) imaging technology was used to understand the distribution and migration of moisture in round bamboo in the course of drying. The results indicated that water content has a significant correlation with the CT value, which can be used to achieve rapid determination of water content. The radial water content of samples gradually decreased from bamboo green (outer) to bamboo yellow (inner). The axial water content was high in the middle and low on both ends. As the water content decreased, the axial moisture distribution was consistent. The internode moisture mainly moved from the junction of bamboo yellow and bamboo partition, entered the adjacent cavity, and then gradually moved outward. Thus, the microwave drying method can effectively achieve industrial drying of round bamboo and prevent cracking.
\end{abstract}

Keywords: Round bamboo; Microwave drying; CT scanning; Moisture migration

Contact information: a: College of Forest and Landscape, Anhui Agricultural University, Hefei, China, 230036; b: International Centre for Bamboo and Rattan, Beijing, China, 100102; c: Hubei Academy of Forestry, Wuhan 430075 China; d: Hubei Mufushan Mountain Bamboo Forest Ecosystem Research Station, Xianning 437100 China; *Corresponding author: feibenhua@icbr.ac.cn; \#Co-author: The authors contributed equally to this work

\section{INTRODUCTION}

Bamboo plants are rich in resources and widely used due to their characteristics of strong photosynthesis and fast growth. Due to the good physical and mechanical properties and processing properties, high strength and good toughness, bamboo has been widely used in high value-added fields such as construction and engineering (Sharma et al. 2015; Xia and Sanjayan 2016; Vorontsova 2018; Hong et al. 2020; Hu et al. 2020). Round bamboo is hollow and a functional biomaterial with a natural multi-level structure (Wegst et al. 2015). On the macroscopic scale, round bamboo is a typical natural fiber-reinforced composite material with thick-walled bamboo fibers as the reinforcing phase and thinwalled porous basic structure as the matrix phase. On the microscopic scale, round bamboo is a nanocomposite with microfibrils as the reinforcing phase and lignin and hemicellulose as the matrix phase (Gillis 1969; Bardage et al. 2004; Simmons et al. 2016; Akinyemi et al. 2020). The drying of round bamboo is an important part of its industrial application. Drying characteristics refer to the effects of drying method on resulting properties, such as macroscopic characteristics and microstructure (Liese 2015). Round bamboo drying is important for its efficient use, which can effectively prevent defects such as cracking. 
Conventional round bamboo drying, e.g. air drying or kiln drying, is limited by poor efficiency due to high energy consumption and long cycle times. These methods always bring some problems of long drying times, easy cracking, and serious pollution. The special structure and anisotropic characteristics of round bamboo determine that its drying process is more complicated than wood drying. Improvements in drying procedures should be considered to effectively prevent defects such as deformation and cracking during later use. Microwave drying has advantages of high speed and cleanliness and relies on electromagnetic waves to directly act on the object and heat from the inside, prompting all parts of the medium to obtain heat at the same time, and quickly heating up.

Moisture is a research focus in the field of wood materials, and a complete knowledge system of the relationship between matter and water has been formed (Skaar 1988; Wiberg 1995; Eriksson et al. 2007; Wu and Peng 2007; Siau 2012; Huang et al. 2017; Kang et al. 2019). Moisture changes in the drying process are an important factor that affect the drying quality of round bamboo. Variable water content is the primary reason why round bamboo cannot be used for a long time. When round bamboo is placed in a lower vapor pressure environment, desorption will occur, but in a high vapor pressure environment, absorption occurs. This process of desorption and moisture absorption increases the internal and external water content gradient, causing uneven shrinkage of bamboo green and bamboo yellow. When this force exceeds the compressive strength of the horizontal stripes of the cell, it will crack (Zhan and Avramidis 2017; Jantawee et al. 2018). The density of bamboo can affect its water absorption and speed, and changes in water content can change other characteristics such as density, shrinkage rate, and strength (Foadieng et al. 2017; Huang et al. 2017). Additionally, microwave treatment changes the size of the pores of the material, increases the permeability of the cell wall, increases the routes of moisture migration, and thereby accelerates the movement of internal moisture. This method allows drying to take place uniformly and will not cause defects, such as bamboo cracking (Lv et al. 2019). There have been few related studies on the effects of drying methods on the water content of bamboo, and they are all based on a static idealized angle (Dixon et al. 2018). Up to now, there has been no research on the distribution and dynamic changes of moisture in the drying process of round bamboo.

In this study, with the help of related spectral analysis techniques, the radial and axial distribution of round bamboo moisture at different drying stages was analyzed to explore the moisture diffusion during the drying process of the round bamboo. By combining the macroscopic and microscopic methods, the results revealed the moisture movement mechanism of the round bamboo during the drying process and provided a reference for industrial application of round bamboo.

\section{EXPERIMENTAL}

\section{Materials}

Five-year-old Hong bamboo (Phyllostachys iridescens C. Y. Yao \& S. Y. Chen) was collected from a forest farm of Sihe Township, Guangde County, Xuancheng, Anhui Province, China. According to GB/T15780 (1995), a one-meter long sample of the newly harvested bamboo was chosen from a whole section about $1.5 \mathrm{~m}$ above the ground, and the marked sample was kept clean and even. 


\section{Sample preparation}

The samples were calibrated as follows. A total of 200 samples, each sized as $2 \mathrm{~cm}$ $(\mathrm{L}) \times 1 \mathrm{~cm}(\mathrm{~T}) \times 0.5 \mathrm{~cm}(\mathrm{R})$ were divided into two groups, 100 samples per group with 10 water content gradients and 10 samples per gradient. The samples were dried at different times to prepare different water content gradient samples. In the first step, the samples were subjected to CT scanning and processed to calculate the water content of the samples at various stages, and the relationship between water content and CT value was established. The second step was to prepare the water content gradient sample according to the same method, perform CT scanning, and then taking the scanned value into the model to obtain the predicted value. The dry treatment was performed on the sample to obtain the actual water content of each water content gradient sample. The actual water content value was compared with the predicted value to verify the model accuracy. The experimental samples were processed as follows. In the same batch of test materials, samples of uniform length and diameter of the internodes were selected, and the samples were prepared with $10 \mathrm{~cm}$ lengths between no-imperfections and no damage to the bamboo green. The water content gradient preparation method is the same as above. The samples were prepared separately with radial and axial CT scanning. Cylindrical samples with a sample size of $2 \mathrm{~mm} \times 30$ $\mathrm{mm}$ (diameter $\times$ length) were three-dimensionally scanned under at a high moisture content to understand moisture migration phenomena (Fig. 1).

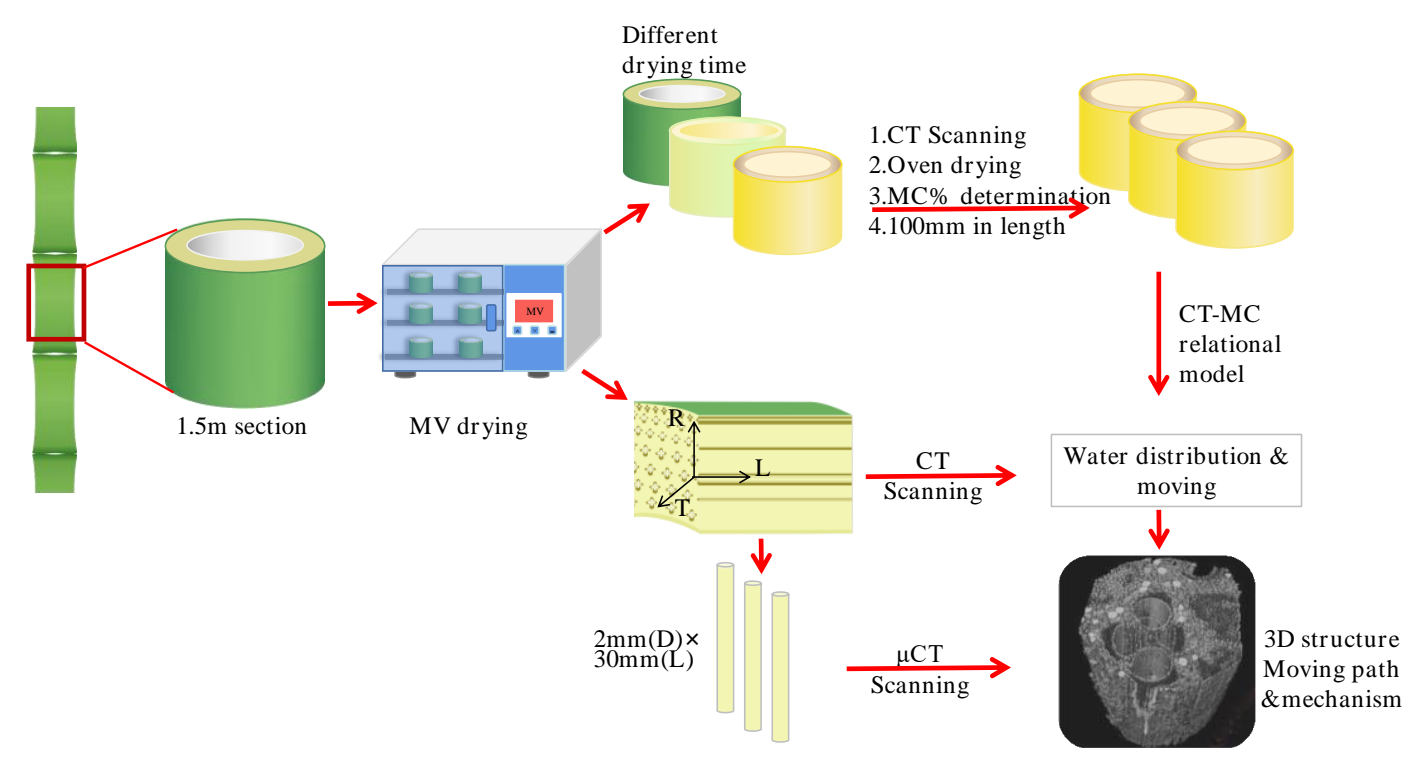

Fig. 1. Schematic illustration for sample preparation (td: drying time with 10 min interval)

\section{Methods}

CT scanning

CT scanning parameters were as follows: $1.25 \mathrm{~mm}$ scan thickness, $1.25 \mathrm{~mm}$ layer spacing, FOV9.6, std reconstruction algorithm, and ambient temperature 20 to $22{ }^{\circ} \mathrm{C}$. The samples were scanned with $\mu$-CT parameters, $150 \mathrm{kV}$ voltage, and 1.8 voxel resolution to realize three-dimensional characterization of the internal structure of the samples.

Drying

The microwave drying equipment at a microwave power of $2 \mathrm{~kW}$, frequency at $2450 \mathrm{MHz}$, and temperature at $70{ }^{\circ} \mathrm{C}$ were used for drying. The sample table was equipped 
with a rotating device and a weighing device with an accuracy of $1 \mathrm{~g}$ to maintain sample motion during the drying process and heated uniformly.

\section{Characterization}

The microscopic morphologies of the dried samples were characterized by field emission scanning electron microscopy (XL30 ESEM FEG, Manufacturer, Beijing, China). A computer tomography device (BrightSpeed Excel Select, Hangwei General Electric Medical System Co., Ltd., Beijing, China) was used to scan samples and establish the relationship between water content and CT value. Hence, the radial and axial moisture distributions were determined. An X-ray three-dimensional microscope (nano voxel, Sanying Precision Instrument Co., Ltd., Tianjin, China) was used to carry out threedimensional sample reconstruction and analyze the migration routes of the moisture.

\section{RESULTS AND DISCUSSION}

\section{Model and Verification of the Relationship between Water Content and CT Value}

Figure 2 shows the model and verification of the sample water content and CT value. As shown in Fig. 2b, the CT value gradually decreased as the water content decreased.
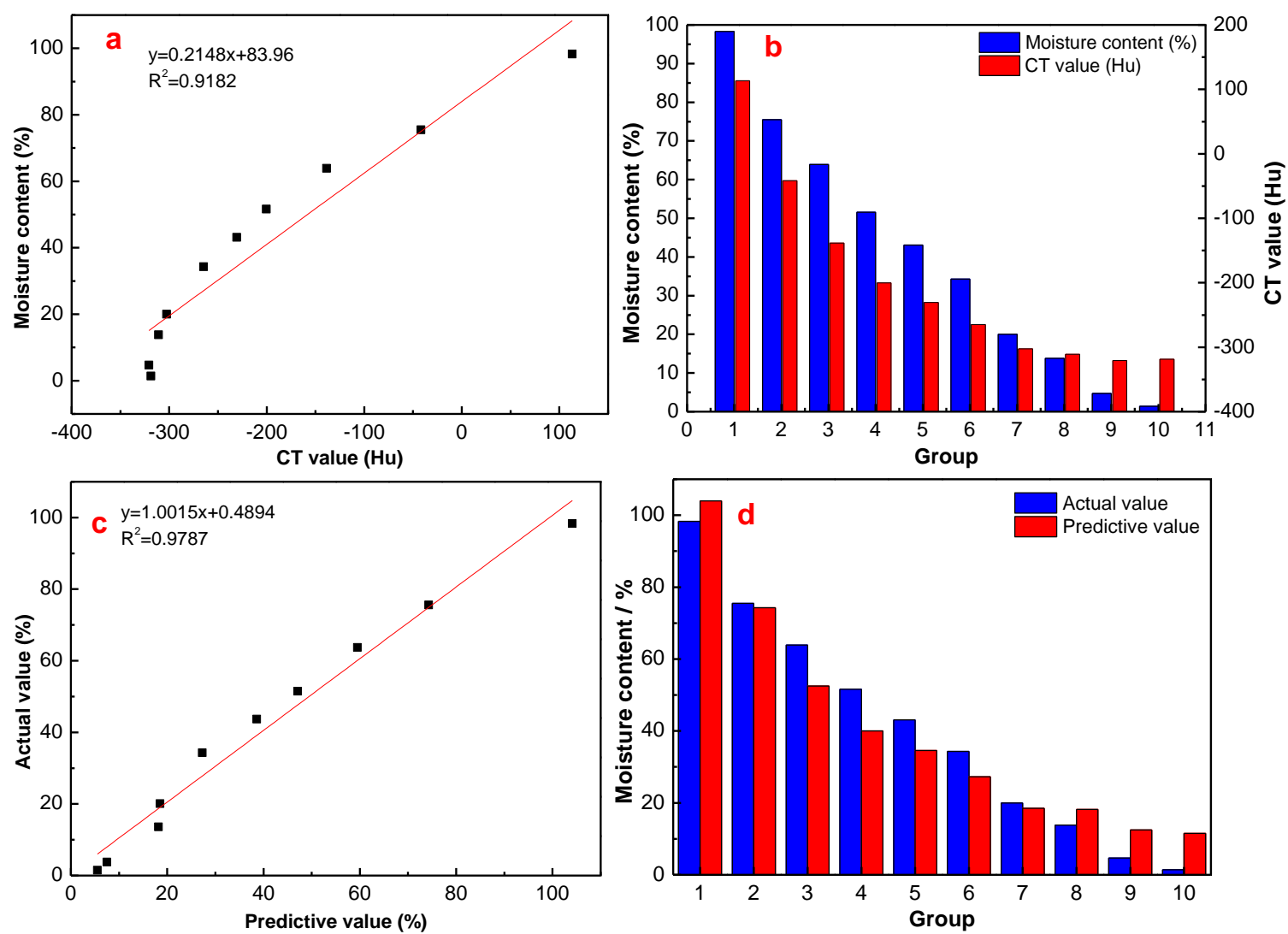

Fig. 2. The model $(a, b)$ and verification $(c, d)$ of water content and $C T$ value 
According to the correlation between the sample water content and the changing CT value, the relationship model of water content and CT value was established using origin software (Fig. 2a). The results of goodness-of-fit ratio show that the linear model was consistent with the changing trends of water content and CT value with a determination coefficient $\mathrm{R}^{2}>0.91$, indicating that the model has a high degree of reliability.

To verify the model accuracy, experimental tests were performed. Figure $2 \mathrm{c}$ shows the fitting curve of the predicted value and measured value of the sample water content. The predicted and measured values had a significant correlation of $\mathrm{R}^{2}>0.97$. Therefore, this model can be used to accurately predict the water content of samples in this experiment.

\section{Moisture Distribution in Round Bamboo Samples}

Figure 3 shows the radial and axial moisture distribution and CT scanning of the sample. As shown in Fig. 3a, the radial water content gradually decreased from the green bamboo to bamboo yellow. At high initial dry water content values, the evaporation of free water was dominant, and the radial water content gradient slowly changed. With longer drying times, free water gradually evaporated, the water content gradually decreased, the radial water content gradient gradually increased, and the water content rate near the bamboo yellow side changed from slow to high. According to the CT scanning of the end surface (Fig. 3c), the vascular bundle is the main channel for moisture transmission. The vascular bundle of the bamboo green part has higher density. The cells are densely arranged, and the cell wall is thick. In contrast, some cells of bamboo yellow are loosely arranged. Because the cell walls are thin and the vascular bundle density is low, the water content of bamboo green is higher than that of bamboo yellow (Huang 2017). In the early stages of drying, the water content of the sample is higher, and the water content of the bamboo green side is higher than that of the bamboo yellow side. Additionally, there are many silicified cells on the bamboo green side, and moisture permeability is poor (Jiang 2007). As drying progresses, the moisture migration of the bamboo green part is slower, and the bamboo yellow part moves faster, increasing the water content gradient between the two. The moisture of the bamboo green part will move to the bamboo yellow part. Therefore, bamboo yellow slowly loses water at early stages of drying (slow change). In late stages of drying, as the water content of the sample is low and the free water in the cell cavity has evaporated (i.e., the fiber saturation point), the lateral movement of moisture stops or is minimal, and the water loss at the bamboo yellow site is faster.

Figure $3 \mathrm{~b}$ shows the axial moisture distribution curve of the sample. In the initial stages of drying, the axial water content was high in the middle and low in both ends. As the water content decreased, the moisture distribution was consistent. Bamboo is mainly composed of vascular bundles and basic tissues and both are in an axial arrangement (no horizontal tissue). The axial permeability of bamboo is much greater than the lateral permeability (Sun et al. 2005; Yao et al. 2011); the water content is high in the middle and low at both ends. When drying is performed, the moisture loss is from the open ends on both sides, and the water loss is faster. The internal moisture gradually moves to the ends through the action of diffusion (Fig. 3d) and due to pressure gradients, forming dynamic inside and outside water content gradients. As the overall water content gradually decreased, the final moisture distribution tended to be consistent. 


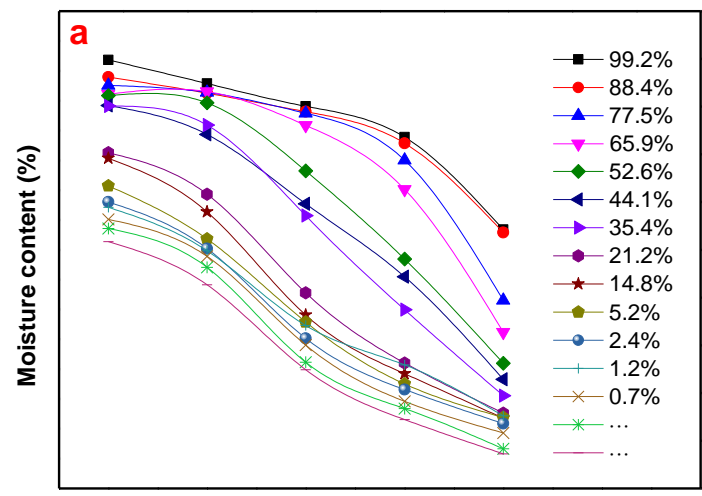

Radial

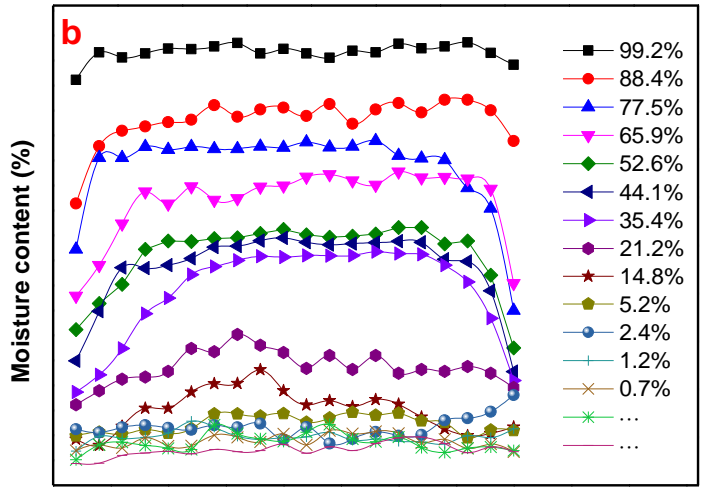

Axial

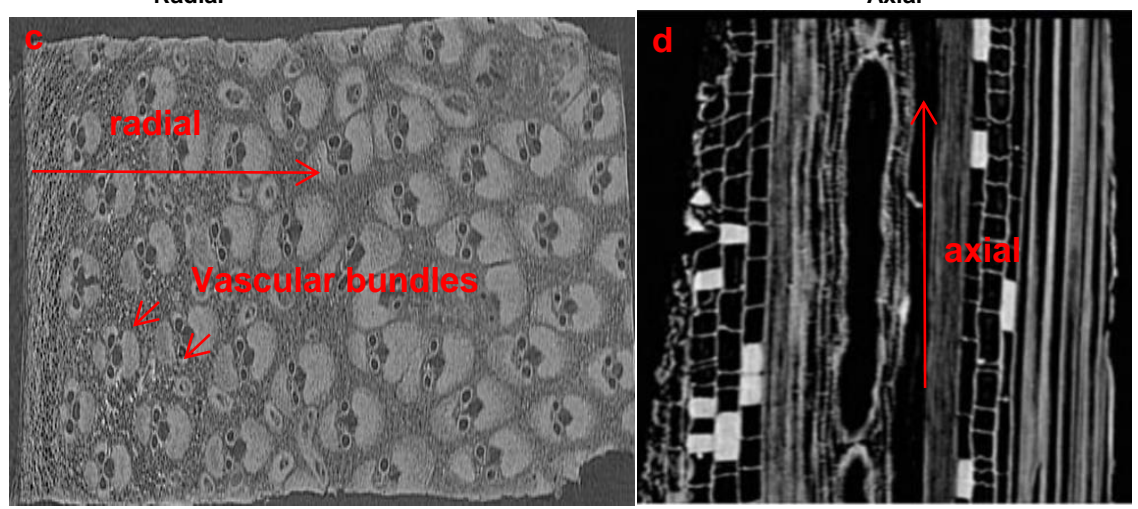

Fig. 3. The radial and axial moisture distribution ( $a$, radial water content profile; $b$, axial water content profile; $c$, the scan of cross section; $d$, the scan of radial section)

\section{Moisture Migration Routes in Round Bamboo}

The round bamboo structure and moisture migration routes are shown in Fig. 4. During the drying process of round bamboo, the moisture was mainly discharged in vertical and horizontal directions. Because the bamboo has no horizontal structure, the discharge of the longitudinal moisture was the majority, and the discharge in the horizontal direction was supplemental. The end is the priority route for the moisture discharge (Fig. 4a). During the drying process, the moisture was discharged from both ends first, forming a water content gradient inside and outside, and the interior moisture penetrated and diffused to the end through lines and other routes. Figure $4 \mathrm{~b}$ is a scan of the end of the sample when saturated with water. The parenchyma cells and catheter were filled with water (bright). As the water content decreased, the end moisture first evaporated, and the catheter and parenchyma cell moisture decreased (dark) (Fig. 4c). Figure $4 \mathrm{~d}$ is the radial macrostructure map of round bamboo. The thick-walled fiber cells are the main part of the bamboo green (outside) with poor permeability, while parenchyma cells of bamboo yellow (inside) account for a relatively large amount, and moisture migration resistance is small. When the water content was high (Fig. 4e), most of the internal moisture moved to the ends, and a small part moved to the inside. As drying progressed, free water in the cell cavity decreased until evaporation was complete (Fig. 4f). 

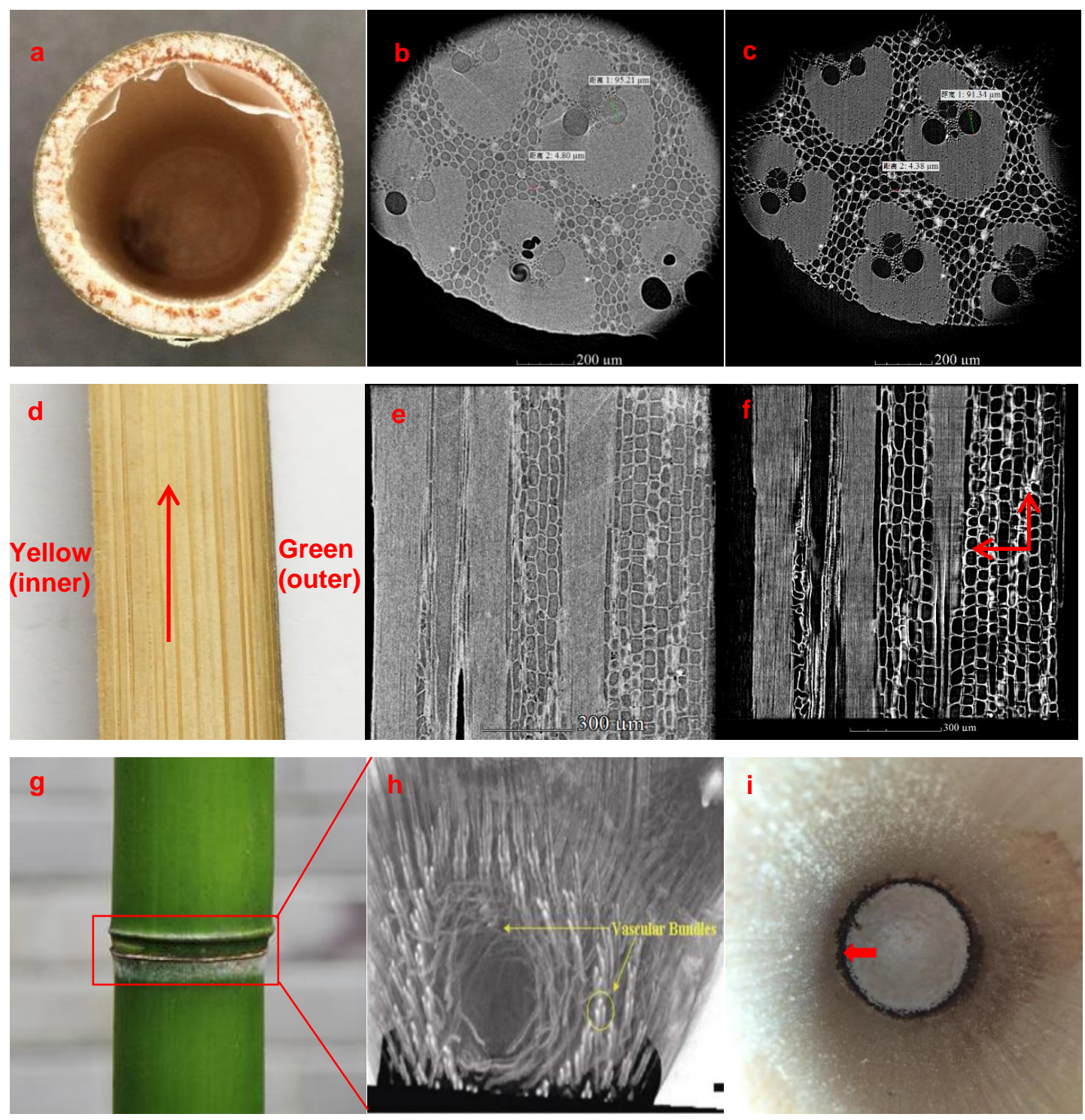

Fig. 4. The round bamboo structure and moisture migration routes (a, sample cross section; $b$, scan of the end of the sample when saturated with water; $c$, out of water of $b$; $d$, radial section of bamboo; e, the scan of the radial section with water; $f$, out of water of $e ; g$, slub appearance; $h$, the scan of slub; i, slub inside)

There are two main directions of horizontal moisture movement. One is movement toward the bamboo green surface with direct discharge (rare), and the other is movement to the bamboo yellow side into the internode sealed cavity, which discharges from the slub. The slub is an important part of bamboo (Fig. 4g), composed of a stalk ring, a scoop ring, and a bamboo partition. The vascular bundle of slub is arranged in a network (Fig. 4h), which has important influence on the moisture movement. The bamboo partition has no convey tissue and is mainly composed of siliceous and calcareous cells with poor permeability. Because the internode is a sealed cavity, as the moisture continues to enter, a large vapor pressure will form between the internodes. Moisture mainly moves from the junction of bamboo yellow and the bamboo partition (Fig. 4i), enters the adjacent cavity, and then gradually move towards the ends until it is expelled. 


\section{Mechanism of Moisture Migration}

The presence of water in round bamboo can be divided into three types: liquid water, which mainly exists in the large capillary system composed of cell cavities; adsorbed water, which exists in the micro-capillary system and is adsorbed on cellulose, hemicellulose, lignin, and hydroxyl groups of other components; and water vapor, which exists in the macro-capillary composed of the unsaturated cell cavity. The migration routes of water primarily include macro-capillary structure, mainly composed of cell cavity and cell wall (Fig. 5a); capillary structure, composed of cell cavity and discontinuous cell wall (Fig. 5b); and a continuous micro-capillary structure formed by the cell wall (Fig. 5c). The structures are related to each other to form a unified capillary system (Walker 1993; Wang 2003; Liu and Zhao 2012).
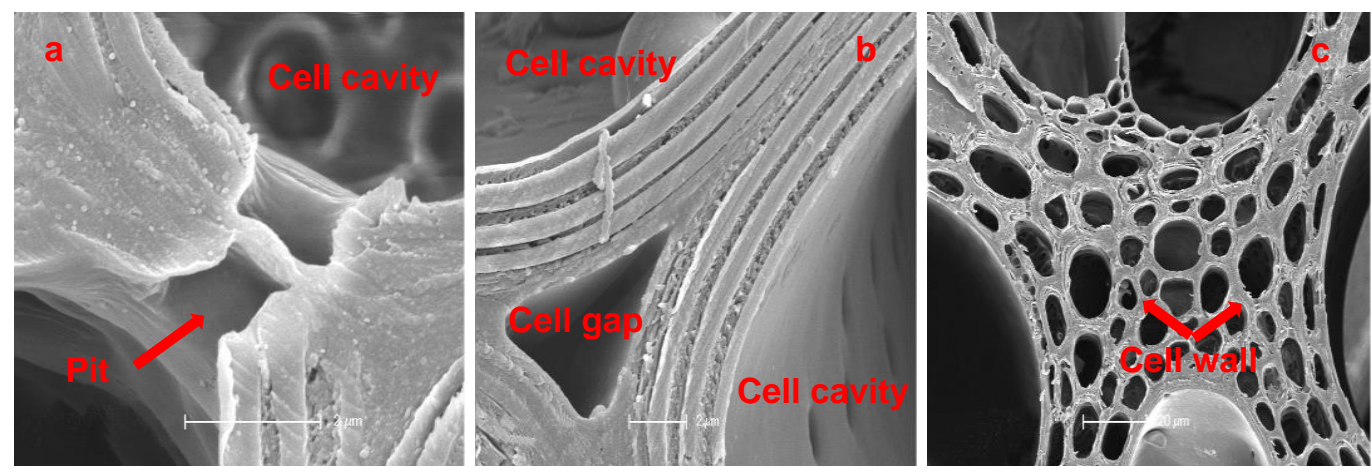

Fig. 5. The migration routes of water (a, macro-capillary structure composed of cell cavity and cell wall; $b$, capillary structure macro-capillary structure composed of cell cavity and cell wall cell cavity and discontinuous cell wall; c, a continuous micro-capillary structure formed by the cell wall)

During the drying process, free water moves first through the internal pore structure and then from the inside to the outside under the driving force. When the temperature is close to or exceeds the boiling point of water, water vapor is quickly generated, and the pressure gradient inside and outside of the cell cavity increases significantly. Under an overall pressure gradient, water vapor moves from a high-pressure area to a low-pressure area, which is similar to the movement of free water, and gas penetration is also taken into account in the movement of water vapor (Walker 1993). Although the density of water vapor is relatively small, the volumetric flow rate is larger under certain pressures. The overall pressure gradient causes the movement of water vapor. In the boiling zone, due to moisture evaporation, there will be continuous water vapor (Waananen et al. 1993). According to Fick's diffusion theory, moisture can freely migrate, usually moving from an area with high water content to an area with low water content, which will produce a water content gradient to achieve moisture content equilibrium (Skaar 1988; Siau 2012). The diffusion rate is also known to increase with increasing temperature. When the temperature rises from $25^{\circ} \mathrm{C}$ to $100{ }^{\circ} \mathrm{C}$, the diffusion rate increases about 37 times. During microwave drying, more water vapor is generated, and diffusion plays an important role.

Unlike traditional drying, with microwave drying the overall pressure gradient is the main driving force for water movement. The temperature and pressure are functions of each other, and the temperature and pressure in the sample are greater than the outside, which accelerates the evaporation of the moisture. When the temperature is constant, the greater the pressure difference between inside and outside, the greater the intensity of moisture evaporation. Additionally, heat is absorbed for the water evaporation, which 
reduces the surface temperature of the material, increases the temperature gradient inside and outside the material, and the direction of water movement is consistent with the temperature field, thereby accelerating the water migration rate. Therefore, under the combined effects of temperature gradient, pressure gradient, and water content gradient, microwave drying has advantages of low temperature and fast rates.

\section{CONCLUSIONS}

1. Using X-ray tomography technology, a water content-CT value fitting model was established. Using this model, the bamboo water content can be quickly determined. The radial and axial moisture distribution trends of the samples in different drying stages were studied. The radial water content distribution of the round bamboo gradually decreased from bamboo green to bamboo yellow. The axial water content is high in the middle and low on both ends at early stage of drying. As the water content decreases with drying, the axial moisture distribution tends to be consistent.

2. The moisture migration analysis of round bamboo shows that the moisture was mainly discharged in two directions, vertical and horizontal. Slub is an important part of bamboo, which has an important influence on moisture movement. Moisture mainly moves from the junction of bamboo yellow and the bamboo partition, enters the adjacent cavity, and then gradually moves toward the end until expulsion.

3. The mechanistic analysis of moisture migration shows that moisture mainly moves in the form of free water and water vapor under the action of driving forces (pressure gradient and temperature gradient). During microwave drying, the overall pressure gradient is the main driving force for water movement. Under the combined effects of temperature gradient, pressure gradient, and water content gradient, the diffusion rate of water is accelerated.

\section{ACKNOWLEDGMENTS}

This research was financially supported by 13th Five-Year the National key R\&D project (2016YFD0600904) and (2016YFD0600905), the National Natural Science Foundation (31770599), the effect of key chemical components of round bamboo on cracking (rc372012).

\section{REFERENCES CITED}

Akinyemi, A.-B., Omoniyi, E.-T., and Onuzulike, G. (2020). "Effect of microwave assisted alkali pretreatment and other pretreatment methods on some properties of bamboo fibre reinforced cement composites," Construction and Building Materials 245, 1-9. DOI: 10.1016/j.conbuildmat.2020.118405

Bardage, S., Donaldson, L., Tokoh, C., and Daniel, G. (2004). "Ultrastructure of the cell wall of unbeaten Norway spruce pulp fiber surface," Nordic Pulp Paper Research Journal 19, 448-452.

Dixon, P.-G., Muth, J.-T., Xiao, X., Skylar-Scott, M.-A., Lewis, J.-A., and Gibson, L.J. 
(2018). "3D printed structures for modeling the Young's modulus of bamboo parenchyma," Acta Biomaterialia 68, 90-98. DOI: 10.1016/j.actbio.2017.12.036

Eriksson, J., Johansson, H., and Danvind, J. (2007). "A mass transport model for drying wood under isothermal conditions," Drying Technology 25, 433-439. DOI: 10.1080/07373930601183785

Foadieng, E., Talla, P.-K., Nkamgang, G.-B., and Fogue, M. (2017). "Study of the thermal properties of raffia bamboo vinifera L. Arecaceae," Advances in Materials Science and Engineering 1-10. DOI: 10.1155/2017/9868903

Gillis, P.-P. (1969). "Effect of hydrogen bonds on the axial stiffness of crystalline native cellulose," Journal of Polymer Science Part A2 (1969), 783-794. DOI: 10.1002/pol.1969.160070504

Hong, C., Li, H., Xiong, Z., Lorenzo, R., Corbi, I., Corbi, O., and Zhang, H. (2020). "Review of connections for engineered bamboo structures," Journal of Building Engineering 30 (2020), 101324. DOI: 10.1016/j.jobe.2020.101324

Huang, P., Latif, E., Chang, W.-S., Ansell, M.-P., and Lawrence, M. (2017). "Water vapour diffusion resistance factor of Phyllostachys edulis (Moso bamboo)," Construction and Building Materials 141, 216-221. DOI: 10.1016/j.conbuildmat.2017.02.156

Hu, J., Song, Y., Liu, Y., Evrendilek, F., Buyukada, M., Yan, Y., and Li, L. (2020). "Combustions of torrefaction- pretreated bamboo forest residues: Physicochemical properties, evolved gases, and kinetic mechanisms," Bioresource Technology 304, 122960. DOI: 10.1016/j.biortech.2020.122960

Jantawee, S., Leelatanon, S., Diawanich, P., Vannarat, S., and Matan, N. (2018). "Comparison of techniques for quantification of internal stress within industrial kilndried timber," European Journal of Wood and Wood Products 76, 617-627. DOI: 10.1007/s00107-018-1285-0

Jiang, Z.-H. (2007). Bamboo and Rattan in the World, China Forestry Publishing House, Shenyang.

Kang, X., Kirui, A., Widanage, M.-C.-D., Mentink, V. F., Cosgrove, D.-J., and Wang, T. (2019). "Lignin-polysaccharide interactions in plant secondary cell walls revealed by solid-state NMR," Nature Communications 10, 347. DOI: 10.1038/s41467-01808252-0

Liese, W. (2015). Bamboo: The Plant and its Uses, Springer, Amsterdam.

Liu, Y.-X., and Zhao, G.-J. (2012). Wood, China Forestry Publishing House, Beijing.

Lv, H., Chen, X., Liu, X., Fang, C., Liu, H., Zhang, B., and Fei, B. (2018). "The vacuumassisted microwave drying of round bamboos: Drying kinetics, color and mechanical property," Materials Letters 223, 159-162. DOI: 10.1016/j.matlet.2018.04.038

Sharma, B., Gatoo, A., Bock, M., and Ramage, M.-H. (2015). "Engineered bamboo for structural applications," Construction and Building Materials 81, 66-73. DOI: 10.1016/j.conbuildmat.2015.01.077

Siau, F. (2012). Transport Processes in Wood, Springer, Berlin. DOI: 10.1007/978-3642-69213-0

Simmons, T.-J., Mortimer, J.-C., Bernardinelli, O.-D., Pöppler, A.-C., and Brown, S.-P. DeAzevedo, E. R., Dupree, R., and Dupree, P. (2016). "Folding of xylan onto cellulose fibrils in plant cell walls revealed by solid-state NMR," Nature Communications 7, 13902. DOI: 10.1038/ncomms13902

Skaar, C. (1988). Wood-water Relation, Springer, Berlin.

Sun, Z.-B., Yang, Y., and Gu, L.-B. (2005). "Study on liquid permeability of 
Dendrocalamus giganteus under normal pressure," China Forest Products Industry 17-19.

Vorontsova, M. (2018). World Checklist of Bamboo and Rattans, Science Press, Beijing. Waananen, K.-M., Litchfield, J.-B., and Okos, M.-R. (1993). "Classification of drying models for porous solids," Drying Technology 11, 1-40. DOI: 10.1080/07373939308916801

Walker, J.-C.-F. (1993). "Water and wood," in: Primary Wood Processing. Principles and Practice, J. C. F. Walker, B. G. Butterfield, J. M. Harris, T. A. G. Landrish, and J. M. Uprichard (eds.), Springer, pp. 68-94.

Wang, X.-M. (2003). Wood Shrinkage, China Forestry Publishing House, Beijing.

Wegst, U.-G., Bai, H., Saiz, E., Tomsia, A.-P., and Ritchie, R.-O. (2015). "Bioinspired structural materials," Nature Materials 14, 23-36. DOI: 10.1038/nmat4089

Wiberg, P. (1995). "Moisture distribution changes during drying," European Journal of Wood and Wood Products 53, 402-402. DOI: 10.1007/s001070050118

Wu, D., and Peng, X.-F. (2007). "Investigation of water migration in porous material using micro-CT during wetting," Heat Transfer Research 36, 198-207. DOI: 10.1002/htj.20156

Xia, M., and Sanjayan, J.-G. (2016). "Method of formulating geopolymer for 3D printing for construction applications," Materials and Design 110, 382-390. DOI: org/10.1016/j.matdes.2016.07.136

Yao, L.-H., Wang, X.-M., and Fei, B.-H. (2011). "Study on permeability coefficient of different bamboo/fir veneer surface," Advanced Materials Research 1634-1637.

Zhan, J., and Avramidis, S. (2017). "Evaluation strategy of softwood drying stresses during conventional drying: A 'mechano-sorptive creep gradient' concept," Wood Science and Technology 51, 1033-1049. DOI: 10.1007/s00226-017-0937-2

Article submitted: January 28, 2021; Peer review completed: February 28, 2021; Revised version received and accepted: March 22, 2021; Published: July 12, 2021.

DOI: 10.15376/biores.16.3.5915-5925 